\title{
Corrigendum: How and Why Do Students Use Learning Strategies? A Mixed Methods Study on Learning Strategies and Desirable Difficulties With Effective Strategy Users
}

\author{
Sanne F. E. Rovers*, Renée E. Stalmeijer, Jeroen J. G. van Merriënboer, \\ Hans H. C. M. Savelberg and Anique B. H. de Bruin
}

School of Health Professions Education, Maastricht University, Maastricht, Netherlands

Keywords: problem-based learning, desirable difficulties, self-regulated learning, learning strategies, mixed methods\&lt, research methodology, grounded theory analysis

\section{A Corrigendum on}

How and Why Do Students Use Learning Strategies? A Mixed Methods Study on Learning Strategies and Desirable Difficulties With Effective Strategy Users by Rovers, S. F. E., Stalmeijer, R. E., van Merriënboer, J. J. G., Savelberg, H. H. C. M., and de Bruin, A. B. H. (2018). Front. Psychol. 9:2501. doi: 10.3389/fpsyg.2018.02501

OPEN ACCESS

Approved by:

Frontiers Editorial Office,

Frontiers Media SA, Switzerland

*Correspondence:

Sanne F. E. Rovers s.rovers@maastrichtuniversity.nl

Specialty section

This article was submitted to Educational Psychology, a section of the journal

Frontiers in Psychology

Received: 31 January 2020 Accepted: 03 February 2020 Published: 20 February 2020

Citation:

Rovers SFE, Stalmeijer RE, van Merriënboer JJG, Savelberg HHCM and de Bruin $A B H(2020)$

Corrigendum: How and Why Do Students Use Learning Strategies? A Mixed Methods Study on Learning Strategies and Desirable Difficulties

With Effective Strategy Users.

Front. Psychol. 11:261.

doi: 10.3389/fpsyg.2020.00261
In the original article, there was an error. The article states that "Results from the analysis were discussed with the second and fourth author. Finally, in a process of selective coding by the first, second and fourth author, themes were related to each other to come to an overarching model of the data" (p. 4).

However, as stated correctly in the Author Contributions, coding was conducted in collaboration between the first, second and last (i.e., fifth instead of fourth) author. Results from the analysis were discussed with the third and fourth author.

A correction has been made to the Methods section, subsection Analysis, Paragraph 2:

Initial, open coding was done by the first author. This was done in a line-by-line fashion, in which representative codes were assigned to the participants' utterances. During this process, several meetings were held with the second and last author to discuss the codes. After arriving at an initial codebook, codes were related to each other in a process of axial coding. During this process, codes were compared and contrasted with each other, looking for connections in order to create themes from overlapping codes. This step was initially done by the first author, with the second and last author each coding a non-overlapping $25 \%$ of the codebook to ensure rigor. Findings from this step were discussed until consensus was reached. Results from the analysis were discussed with the third and fourth author. Finally, in a process of selective coding by the first, second and last author, themes were related to each other in order to come to an overarching model of the data.

The authors apologize for this error and state that this does not change the scientific conclusions of the article in any way. The original article has been updated.

Copyright (๑) 2020 Rovers, Stalmeijer, van Merriënboer, Savelberg and de Bruin. This is an open-access article distributed under the terms of the Creative Commons Attribution License (CC BY). The use, distribution or reproduction in other forums is permitted, provided the original author(s) and the copyright owner(s) are credited and that the original publication in this journal is cited, in accordance with accepted academic practice. No use, distribution or reproduction is permitted which does not comply with these terms. 